\title{
Hydrodynamical conditions in the melt at the growth of sapphire and YAG crystals by horizontal directed crystallization
}

\author{
S.V.Nizhankovskyi, A.V.Tan'ko \\ Institute for Single Crystals, STC "Institute for Single Crystals", National \\ Academy of Sciences of Ukraine, 60 Lenin Ave., 61001, Kharkiv, Ukraine
}

\section{Received January 12, 2015}

\begin{abstract}
Investigated are the hydrodynamical conditions in the melt at the growth of sapphire and yttrium-aluminum garnet (YAG) by the method of horizontal directed crystallization. Specific features of the formation of convective structures depending on the temperature conditions, geometrical parameters of the melt zone and crystal growth stage, are established. It is shown that at the growth of massive $(\geq 40-50 \mathrm{~mm})$ sapphire and YAG crystals the two-layer structure of the melt flow may be formed at the crystallization front.

Keywords: simulation, convection, sapphire, YAG, HDC method.
\end{abstract}

\begin{abstract}
Исследованы гидродинамические условия в расплаве при росте кристаллов сапфира и иттрий-алюминиевого граната (YAG) методом горизонтальной направленной кристаллизации. Установлены особенности формирования конвективных структур в зависимости от температурных условий, геометрических параметров зоны расплава и стадии роста кристаллов. Показано, что при росте массивных ( $\geq 40-50$ мм) кристаллов сапфира и YAG возможно возникновение двухслойной структуры течения расплава у фронта кристаллизации.
\end{abstract}

Гідродинамічні умови у розплаві при вирощуванні кристалів сапфіра та YAG методом горизонтальної спрямованої кристалізації. C.В.Ніжанковський, А.В.Танько.

Досліджено гідродинамічні умови у розплаві під час росту кристалів сапфіра та ітрій-алюмінієвого граната (YAG) методом горизонтальної спрямованої кристалізації. Встановлено особливості формування конвективних структур в залежності від температурних умов, геометричних параметрів зони розплаву і стадії росту кристалів. Показано, що під час росту масивних ( $\geq 40-50$ мм) кристалів сапфіра та YAG можливе виникнення двошарової структури течії розплаву біля фронту кристалізації.

\section{Introduction}

One of the methods most often used for the obtaining of large-size sapphire $\left(\mathrm{Al}_{2} \mathrm{O}_{3}\right)$ crystals is horizontal directed crystallization (HDC). This method was used to develop a technique for the making of single-crystalline sapphire windows with record dimensions $-350 \times 500 \times 30 \mathrm{~mm}^{3}$ [1]. The method of HDC is also promising for the growth of large crystals of rear-earth aluminum garnets ReAG and of their solid solutions $(\mathrm{Re}=\mathrm{Y}, \mathrm{Ce}, \mathrm{Pr}, \mathrm{Nd}, \mathrm{Yb}, \mathrm{Er}, \mathrm{Lu}$, etc.) which are widely used in laser and scintillation engineering [2]. Moreover, YAG:Ce crystals may be utilized as luminescent converters for high-power white light diodes.

The main problem which arises at the growth of large-size multi-component activated crystals is the obtaining of high optical quality and uniform distribution of their functional characteristics in the crystal bulk. This is mainly caused by non-uniform- 
ity and non-stationarity of the hydrodynamical conditions, mass transfer in the melt near the crystallization front (CF) leading to non-uniform distribution of the activator, matrix components and point defects, formation of second-phase inclusions in the crystals $[3,4]$. Therefore, optimization of the conditions of mass transfer in the melt is one of the main ways for raising the crystal quality.

Direct experimental investigation of the hydrodynamical processes which accompany the growth of high-melting oxide crystals is greatly complicated, since their melting temperature is $\sim 2000^{\circ} \mathrm{C}$. Therefore, the main means for studying such crystals is simulation. At present there exist a large number of papers devoted to numerical simulation of convection of the melt at the growth of oxide single crystals by the Czochralsky, Kyropoulos and HEM methods (see e.g. [3-6]). While studying the conditions of the growth of sapphire and garnet crystals by the HDC method the melt mixing was neglected, or a convection was considered only qualitatively $[4,7,8]$. It is natural to assume that the approximation of immovable melt may be disturbed at the rise of the melt volume and the growth of large-size crystals. It is also known that, in contrast to the classical Rayleigh problem of convective stability of horizontal liquid layer in the field of gravitational forces, in the real case of horizontal directed crystallization there take place thermocapillary Marangoni convection and thermal convection of the melt caused by the presence of non-uniform temperature field [9, 10].

The method of HDC is characterized by asymmetry of the thermal conditions with respect to the horizontal plane of the crucible containing the melt. Therefore, there may arise a wide variety of hydrodynamical phenomena and structures which lead to the formation of inhomogeneities in the composition and structure of the crystals, non-linear temperature distribution and the presence of blocks in the crystals.

The main goal of the present work is numerical simulation and comparative analysis of the hydrodynamical conditions in the melt at the growth of sapphire and yttrium-aluminum garnet (YAG) crystals by the method of HDC.

This will allow to establish the main features of the hydrodynamical conditions and to optimize the technology of the growth of large-size sapphire and garnet crystals by the method of HDC.

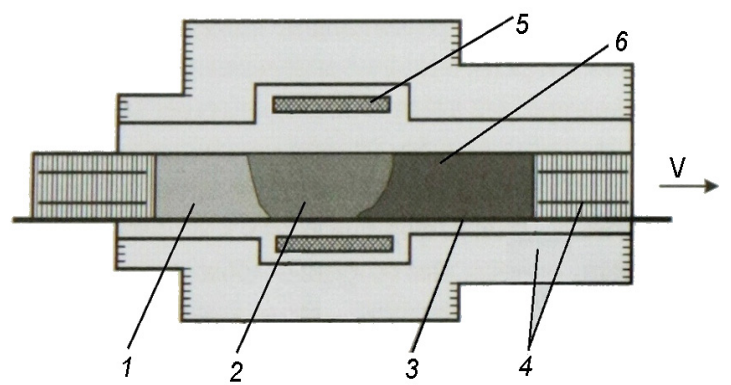

Fig. 1. Scheme of HDC method: 1 - starting material, 2 - melt, 3 - crucible, 4 - thermal shields, 5 - heater, 6 - crystal.

\section{Problem statement}

The essence of the HDC method schematically shown in Fig. 1 is the following. The starting material to be crystallized is placed into a boat-shaped crucible which moves through the zone of heating where the material is melted and then crystallized on a single-crystalline seed mounted in the front part of the crucible.

Experimental investigations show that for the HDC method the crystallization conditions are not stationary. In the process of crystal pulling accompanied with the rise of heat withdrawal through the crystal, gradual increase of the melt overheating degree, change in the length and height of the melt zone. Under such conditions there will be also observed changes in the hydrodynamical conditions, which character can be estimated by analyzing the similarity numbers:

$$
\begin{gathered}
R a^{-}=\frac{g \beta \Delta T L^{3}}{v \chi}, \\
R a^{\perp}=\frac{g \beta \Delta T h^{3}}{v \chi}, \\
M a=-\frac{d \sigma \Delta T L}{d T \mu \chi} .
\end{gathered}
$$

For the analysis it is convenient to introduce the "horizontal" $R a^{-}$and "vertical" $R a^{\perp}$ Rayleigh numbers [11]. The character of thermogravitational convection of the melt under the action of the horizontal temperature gradient taking into account the melt length $L$ is defined by $R a^{-}$. Taking into account changes in the height of the melt $h$ is defined by $R a^{\perp}$. Ma, the Marangoni number, characterizes the possibility of the formation of convective flow in the liquid under the action of thermocapillary forces on the upper free surface of the melt.

In these relations $g$ is the free fall acceleration, $\beta$, the coefficient of volumetric ex- 
pansion of the melt, $\Delta T$, the melt overheating, $v$, the kinematic viscosity, $\chi$, the temperature conductivity, $h$, the melt height, $\sigma$, the surface tension, $L$, the characteristic length estimated as the half-length of the melt zone: $L_{m z} / 2$.

The calculation of the similarity numbers made on the base of the experimental results obtained while studying the growth conditions (the width of the melt zone, the temperature gradients, the melt overheating degree) for sapphire and YAG crystals with the length $h \approx 50 \mathrm{~mm}$ and the melt zone length $L_{m z}=0-200 \mathrm{~mm}$ shows that the character of the melt flow changes in the process of crystallization. The latter may be considered to have three stages: initial shouldering, main and final - crystallization of the melt in the back part of the crucible (Fig. 2).

At the initial and final stages of the growth characterized by the least values of the melt zone $\left(L_{m z} \leq 100-120 \mathrm{~mm}\right)$ and of the similarity numbers, the melt flow may be considered quasi-stationary [12].

At the second stage, due to the increase of the melt zone width and the melt overheating degree, the intensity of convection in $\mathrm{Al}_{2} \mathrm{O}_{3}$ melt reaches its maximum value (the similarity numbers may run into $\sim 10^{6}-10^{7}$ ), and there occurs the change-over from quasi-stationarity to turbulence. Turbulent convection is characteristic of the growth of massive sapphire crystals with relatively large values of $h$ and $L_{m z}$.

Convection in YAG melt essentially differs from that in $\mathrm{Al}_{2} \mathrm{O}_{3}$ melt. For $Y A G$ the values of similarity numbers lie within the limits of $10^{5}$, convection in YAG melt is stationary and stable (Fig. 2).

In the process of crystal pulling the characteristic height diminishes. This is connected with different densities of the melt and the crystal: for $\mathrm{Al}_{2} \mathrm{O}_{3}$ and $Y A G$ the melt height at the final growth stage decreases by $\sim 24 \%$ and $\sim 12 \%$, respectively, and this also influences the character of the melt flow.

The duration of the growth stages is defined by the lengths of the crucible and the melt zone.

Thus, the hydrodynamical problem in the stationary formulation can be solved for $\mathrm{Al}_{2} \mathrm{O}_{3}$ melt for the first and the final growth stages, whereas for YAG melt it can be solved for the whole growth cycle.

As follows from consideration of the general scheme of the thermal unit for the
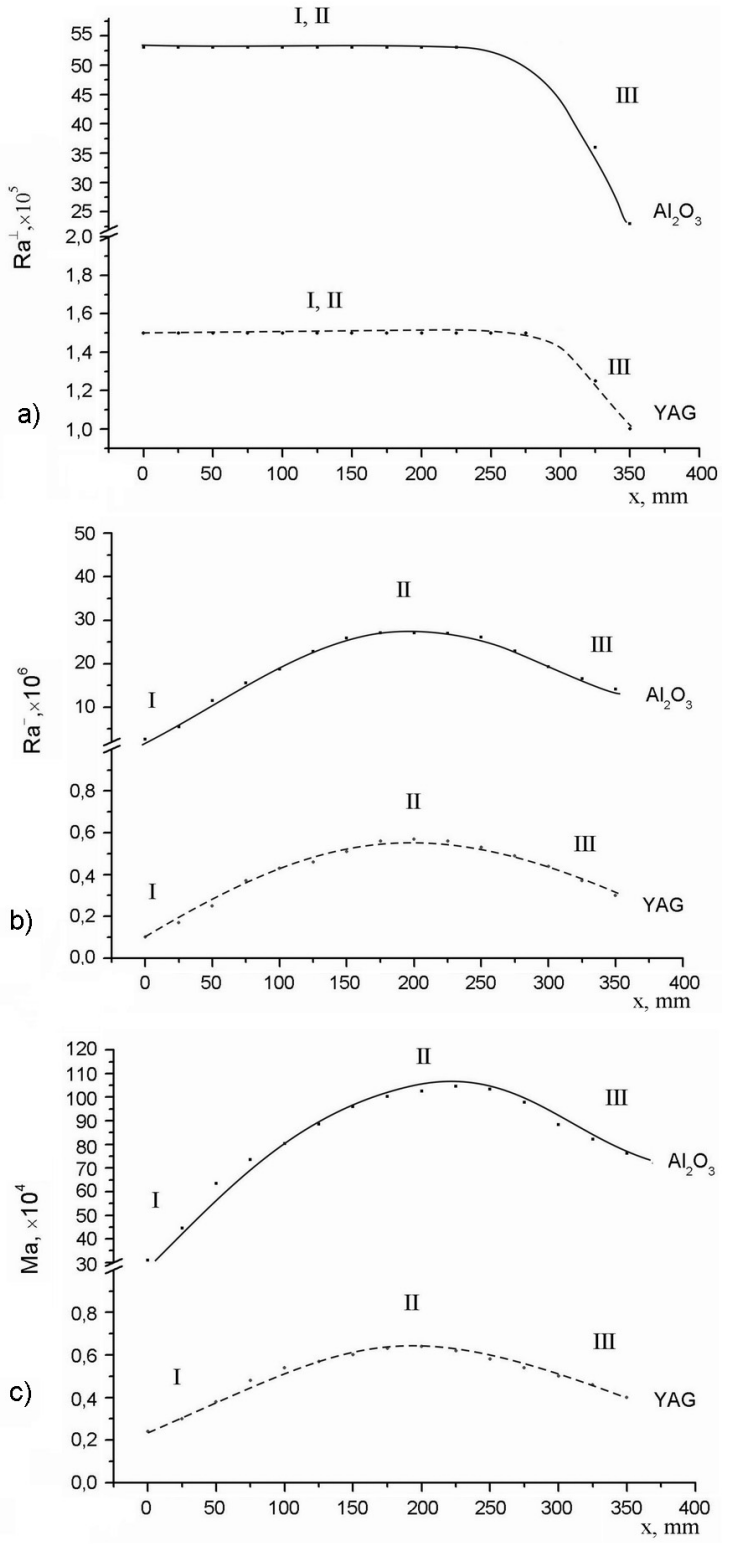

Fig. 2. Change in the values of similarity numbers depending on the stage of $\mathrm{Al}_{2} \mathrm{O}_{3}$ and YAG crystal growth.

growth of crystals by the method of HDC, the temperature conditions have the mirror symmetry with respect to the vertical plane the crystal growth direction. At rather low radial gradients this allows to confine the consideration to the two-dimensional problem [13]. In this case the influence of the crucible walls is neglected.

The hydrodynamical problem of the melt convection in a boat-shaped crucible was solved in the Boissinesq approximation. Thereat, there was used the linear approximation of the temperature dependence of the melt density: 
Table. Physical characteristics of $\mathrm{Al}_{2} \mathrm{O}_{3}$ and $\mathrm{YAG}$ melts, crystals and starting materials

\begin{tabular}{||c|c|c||}
\hline Physical properties & $\mathrm{Al}_{2} \mathrm{O}_{3}[14,15]$ & YAG $[16-18]$ \\
\hline \multicolumn{2}{|c|}{ Melt } & $3990-0.29 \cdot(T-2240)$ \\
$\lambda, \mathrm{kg} / \mathrm{m}^{3}$ & $3030-1.08 \cdot(T-2327)$ & 4.0 \\
$c_{p}, \mathrm{~J} / \mathrm{kg} \cdot \mathrm{K}$ & 2.05 & 800 \\
$\beta, 1 / \mathrm{K}$ & 1260 & $1.8 \cdot 10^{-5}$ \\
$\eta, \mathrm{kg} / \mathrm{m} \cdot \mathrm{s}$ & $3.56 \cdot 10^{-4}$ & 0.46 \\
$\sigma, \mathrm{N} / \mathrm{m}$ & $0.0000067 \cdot \exp (21079 / T)$ & 0.781 \\
\hline$\rho, \mathrm{kg} / \mathrm{m}^{3}$ & $0.67-3 \cdot 10^{-3}(T-23227)$ & 4560 \\
$c_{p}, \mathrm{~J} / \mathrm{kg} \cdot \mathrm{K}$ & $\mathrm{Crystal}$ & 800 \\
\hline \multicolumn{2}{|c|}{3980} & 4160 \\
\hline$\rho, \mathrm{Wg} / \mathrm{m}^{3}$ & 760 & 8 \\
$c_{p}, \mathrm{~J} / \mathrm{kg} \cdot \mathrm{K}$ & Starting material & 700 \\
\hline
\end{tabular}

$$
\rho(T)=\rho_{0}(1-\beta T) .
$$

Here $\rho_{0}$ is the melt density at the melting temperature $T_{m}$, $T$, the deviation from $T_{m}$.

The hydrodynamical equations for incompressible liquid in two-dimensional formulation:

1. The Navier-Stokes equation:

$$
\begin{gathered}
V_{x} \frac{\partial V_{x}}{\partial x}+V_{y} \frac{\partial V_{x}}{\partial y}=-\frac{1 \partial P}{\rho_{0} \partial x}+v\left(\frac{\partial^{2} V_{x}}{\partial x^{2}}+\frac{\partial^{2} V_{x}}{\partial y^{2}}\right) \\
V_{x} \frac{\partial V_{y}}{\partial x}+V_{y} \frac{\partial V_{y}}{\partial y}= \\
=-\frac{1 \partial P}{\rho_{0} \partial y}+v\left(\frac{\partial^{2} V_{y}}{\partial x^{2}}+\frac{\partial^{2} V_{y}}{\partial y^{2}}\right)+\beta T g
\end{gathered}
$$

2. The heat conduction equation:

$$
V_{x} \frac{\partial T}{\partial x}+V_{y} \frac{\partial T}{\partial y}=\lambda\left(\frac{\partial^{2} T}{\partial x^{2}}+\frac{\partial^{2} T}{\partial y^{2}}\right)
$$

3. Equation of incompressibility:

$$
\frac{\partial V_{x}}{\partial x}+\frac{\partial V_{y}}{\partial y}=0
$$

where $V$ is the field of velocities in the melt; $P$, the pressure; $v$, the kinematic viscosity, $\lambda$, the thermal conductivity.

The boundary conditions:

- the condition of sticking at the crystallization front and at the crucible walls: $V=0$;
- the temperature conditions at the upper free melt surface $\left(T_{u}\right)$ and at the crucible bottom $\left(T_{b}\right)$ were assumed to vary according to the parabolic law from a certain maximum value, $T_{u}$ and $T_{b}$, respectively, to the melting temperature at the CF, $T_{f}$. There were considered two cases of overheating: $\left(T_{u}-T_{b}>0\right)$ and $\left(T_{u}-T_{b}<0\right)$;

- the condition set for taking into account the thermocapillary force and the Marangoni convection at the free upper boundary (melt - vacuum):

$$
\left\{\begin{array}{l}
\frac{\partial V_{x}}{\partial x}=\frac{M a}{P r} \cdot \frac{\partial T}{\partial x} \\
V_{y}=0
\end{array}\right.
$$

where $\operatorname{Pr}$ is the Prandtl number:

$$
\operatorname{Pr}=\frac{v}{\chi}
$$

For the length and height of the melt there were used the fixed values characteristic of the process of crystal growth by the method of HDC: the height $h=20-$ $100 \mathrm{~mm}$, the length $L_{m z}=100-250 \mathrm{~mm}$. The physical characteristics of sapphire and yttrium-aluminum garnet used in the calculations are presented in Table.

Since sapphire crystals do not possess sufficient transparency to thermal radiation, for them one can introduce the effective coefficient of thermal conductivity - 

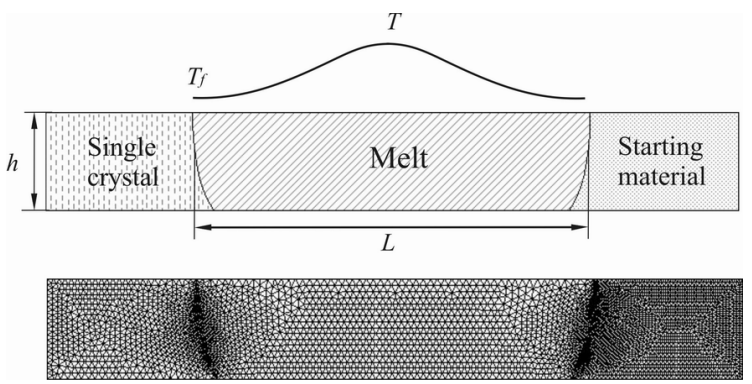

Fig. 3. Geometry, boundary conditions and mesh of the computational domain: crystal, melt and starting material.

the sum of the phonon and radiation conductivity components:

$$
\lambda_{\text {eff }}=\lambda_{p h}+\lambda_{\text {rad }}
$$

In the direction along the crystal axis thermal radiation transfer is predominating. According to [19], for sapphire

$$
\frac{\lambda_{\text {rad }}}{\lambda_{\text {ph }}} \approx 10(\text { at } T=2323 K) \text {. }
$$

The melting temperatures of sapphire and YAG (2323 $\mathrm{K}$ and $2240 \mathrm{~K}$, respectively) and their optical absorption spectra are close enough. Therefore, the condition (8) was also used for the garnet.
The problem was numerically solved by means of finite-element analysis using the program [20]. To build the general finiteelement model we used the regular mesh with triangular elements (Fig. 3). The optimum value of the calculated grid density was determined on the base of 8 test calculations at different meshing of the area into finite elements. According to the calculation results we built the dependence of the required value (i.e. the flow velocity) for the given point on the quantity of the "partition elements and chose the optimum grid density.

Thereat, there were taken into account the bulk and surface forces acting in the melt. The bulk forces are caused by local changes of melt density in the gravitational field and "switch on" the mechanism of free thermogravitational convection. The temperature gradient on the free melt surface leads to nonuniformity of the surface tension, the appearance of tangential capillary forces, and, consequently, thermocapillary Marangoni convection.

\section{Results and discussion}

The performed simulation makes it possible to establish that the convective structures formed in $\mathrm{Al}_{2} \mathrm{O}_{3}$ and $\mathrm{YAG}$ melts contained in a boat-shaped crucible are defined a)

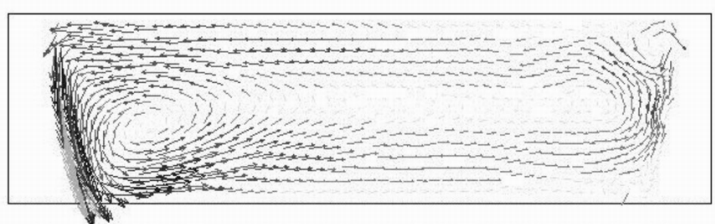

b)

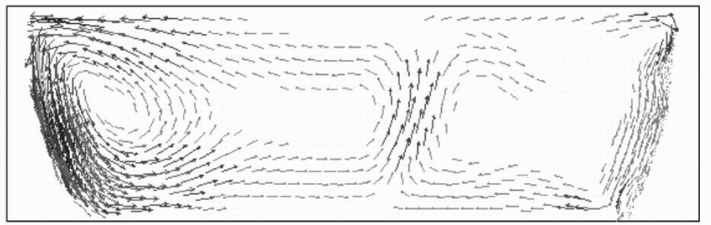

c)

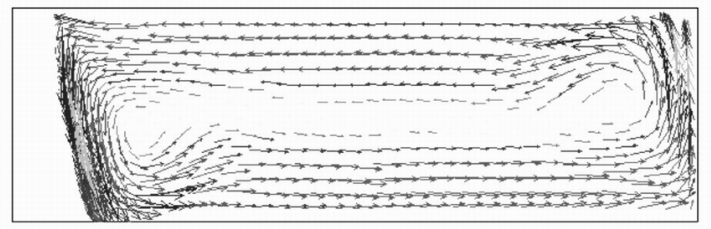

e)

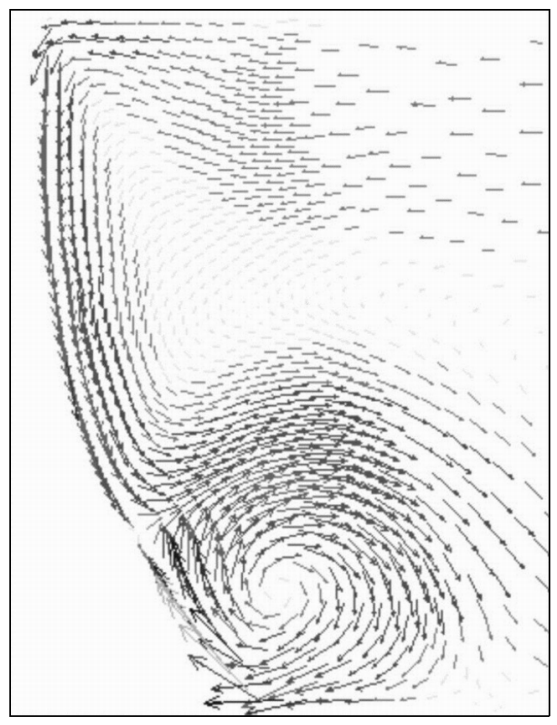

d)

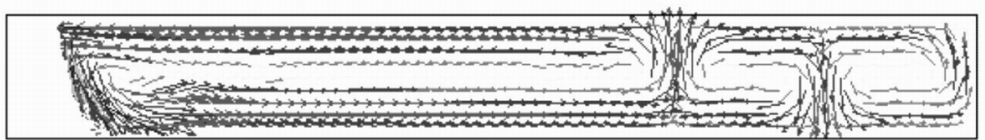

Fig. 4. Types of quasi-stationary flows of $\mathrm{Al}_{2} \mathrm{O}_{3}$ and $\mathrm{YAG}$ melts: a, c) single-vortex, b) double-vortex, d) cellular convection, e) "two-layer" motion in the vicinity of the CF. 


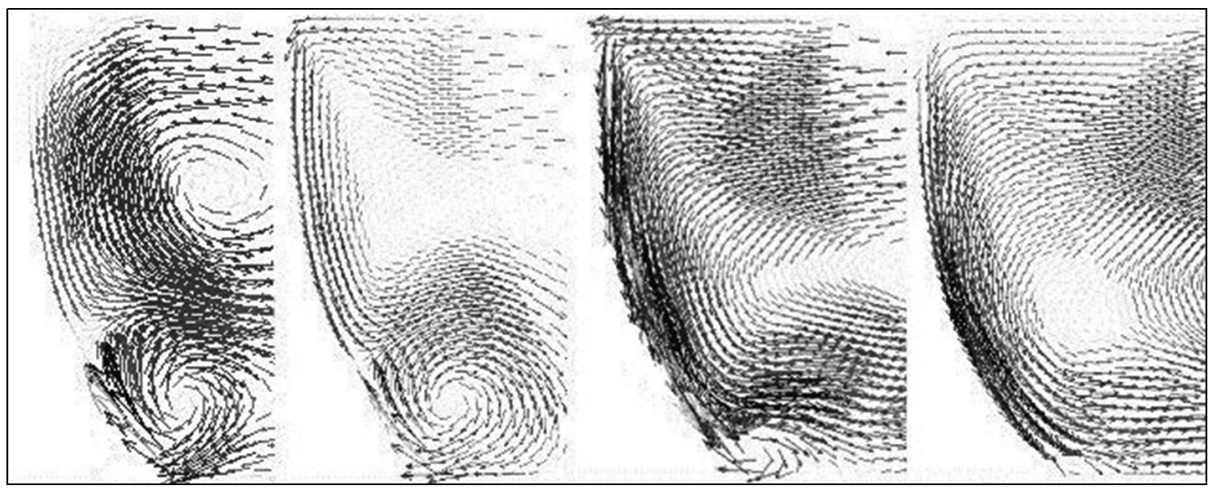

Fig. 5. Flow of $\mathrm{Al}_{2} \mathrm{O}_{3}$ melt in the vicinity of the $\mathrm{CF}$ at the increase of the melt zone length (from the left to the right): $h / L_{m z}=0.3 ; 0.2 ; 0.15 ; 0.12$.

by the extent and direction of overheating (from the upper or from the bottom crucible part), the value of the thermal flow passing through the solid phase (the crystal, the starting material) and the aspect ratio $h / L_{m z}$ (the ratio of the melt height to its length). There were established the following types of convective structures: singlevortex (Fig. 4a, c), double-vortex (Fig. 4b, e) and cellular (Fig. 4d). Double-vortex convection has two variants: the vortices may be arranged in series (Fig. 4b), or one of them may be located above the other, thus creating a "two-layer" motion of the melt at the crystallization front (Fig. 4e).

At the initial stage of the growth of sapphire crystal the single-vortex convection is dominating in the melt when overheating is directed from above $\left(\Delta T=T_{u}-T_{b}>0\right)$, whereas double-vortex convection occurs at overheating from the crucible bottom $(\Delta T<0)$. In YAG melt single-vortex convection is observed within wide $h / L_{m z}$ range irrespective of the direction of overheating.

At the main crystal growth stage twoprofile or cellular convection are primarily realized at overheating from the crucible bottom and $h / L_{m z} \leq 0.1-0.2$.

At the final growth stage a noticeable contribution to the formation of the flow structure may belong to the back wall of the crucible. Under certain thermal conditions it creates additional disturbances of the flow, leads to the appearance of convective vortices and changes the flow intensity (Fig. 4c).

Simulation of convection in $\mathrm{Al}_{2} \mathrm{O}_{3}$ melt shows that at $h / L_{m z}<0.1-0.15$ and predominant overheating from the upper part of the crucible the prime mover is thermocapillary force leading to the formation of sufficiently effective Marangoni convection.
As show the simulation results, on the whole the said convection exerts a stabilizing action on $\mathrm{Al}_{2} \mathrm{O}_{3}$ melt flow and impedes the formation of vortices.

Thermogravitational convection is clearly seen to be dominating in YAG melt, which temperature dependence of the surface tension is weaker than that of $\mathrm{Al}_{2} \mathrm{O}_{3}$ melt [17]. Such a distinction in the two main mechanisms of convection also influences the appearance of the vortex in the area adjustment to the crystallization front: in $\mathrm{Al}_{2} \mathrm{O}_{3}$ melt the vortex center is shifted downwards by thermocapillary convection (Fig. 4a), whereas in YAG melt it is shifted to the melt surface due to thermogravitational convection (Fig. 4b).

In comparison with the convection in $\mathrm{Al}_{2} \mathrm{O}_{3}$, the one in YAG melt is more stable. The average flow velocities are lower by a factor of $1.5-2$ than those in $\mathrm{Al}_{2} \mathrm{O}_{3}$. This may effect the quality of the crystal at overheating of the melt from above, due to the condition of sticking at the crucible bottom there may be formed a stagnant area where the melt motion is weak. The values of dynamical viscosity of $\mathrm{Al}_{2} \mathrm{O}_{3}$ and YAG melts differ insignificantly, therefore, the flow of YAG melt is stabilized mainly by its high density and physical characteristic depending on it. For YAG melt a stationary flow is realized at all the crystal growth stages within the whole range of the melt overheating values $\leq 100-120 \mathrm{~K}$. Only during the growth of the crystals from a large melt volume and the aspect ratio $h / L_{m z} \sim 1$ nonstationary convection may occur.

As mentioned above, under certain conditions for $\mathrm{Al}_{2} \mathrm{O}_{3}$ and $\mathrm{YAG}$ "two-layer" motion of the melt may occur at the crystallization front (Fig. 4e). This is most characteristic of the growth of massive crystals $(\geq 40-$ 
$50 \mathrm{~mm})$ at $h / L_{m z} \geq 0.2-0.3$. The appearance of such a convective structure is unfavorable for the growth of the crystals and may lead to the formation of defects and their aggregations [21].

The causes of the formation of the said "two-layer" motion of the melt are bound up with high thermal conductivity of the crystal and different mechanisms of motion of the liquid. In particular, in the upper part of the melt the thermocapillary Marangoni flow is mainly observed, in the lower part of the melt bulk gravitational forces and the buoyant Archimedean force are acting. In the vicinity of the CF the melt is not "captured" within its bulk by thermocapillary convection, and there occurs stratification into two flows: buoyancy-driven convections at the crucible bottom and the thermocapillary flow in the upper part of the melt. Calculations show that the intensity of the lower vortex also strongly depends on the thermal flow passing through the crystal. The double-vortex structure of the flow near the crystallization front may disappear when the melt length rises (Fig. 5). As the free melt surface increases, the flow in the upper part of the melt caused by the thermocapillary Marangoni convection rises, too. Under the influence of such a flow the vortex in the lower part of the crystallization front gradually weakens.

The two-layer motion of the melt at the crystallization front is more pronounced for $\mathrm{Al}_{2} \mathrm{O}_{3}$ melt. Thermocapillary convection in YAG melt is much less developed in comparison with that in sapphire. Therefore, the formation of double-vortex flow of the melt during the growth of garnet crystals may take place only at rather high values of the ratio $h / L_{m z}$ and temperature gradients in the melt.

\section{Conclusions}

The analysis and simulation of a convection based on experimental studies of the conditions of sapphire and YAG crystal growth by the HDC method show that the main distinctions in the structure of the flow of $\mathrm{Al}_{2} \mathrm{O}_{3}$ and YAG melts are bound up with different contribution of thermogravitational and thermocapillary convections. The convection observed in YAG melt is characterized by higher stability than the one in $\mathrm{Al}_{2} \mathrm{O}_{3}$ melt. Therefore, the crystallization front of garnet is less susceptible to temperature fluctuations in comparison with that of sapphire. On the other hand, a slower convective mixing of the melt near the crystallization front of garnet may give rise to accumulation of excessive components of the melt and the formation of the region of concentration overcooling in the second phase inclusions.

\section{References}

1. L.A.Grin, A.T.Budnikov, N.S.Sidelnikova et al., Functional Materials, 20, 111 (2013).

2. S.V.Nizhankovsky, A.Ya.Dan'ko, Yu.V.Zorenko et al., Phys. Solid State, 53, 1542 (2011).

3. M.H.Tavakoli, J. Cryst.Growth, 310, 2955 (2008).

4. S.E.Demina, E.N.Bystrova, V.V.Kalaev et al., Opt. Mater., 30, 62 (2007).

5. Chung-Wei Lu, Pei-Hung Chi, Cryst.Res. Technol., 42, 1259 (2007).

6. Banerjee, Jyotirmay, Muralidhar, J.Cryst. Growth, 286, 2 (2006).

7. Kh.S.Bagdasarov, High-temperature Crystallization from Melt, Fismatlit (2004) [in Russian].

8. M.Putilin, Yu.A.Belyakova, V.P.Golovko, Synthesis of Minerals, v.2, Nedra, Moscow (1987) [in Russian].

9. C.W.Lan, M.C.Su, M.C.Liang, J.Cryst. Growth, 208, 717 (2000).

10. M.C.Liang, C.W.Lan, J.of Crystal Growth, 180, 381 (1997).

11. G.Muller, Crystal Growth from the Melt, Springer-Verlag, Berlin (1988).

12. R.Krishnamurti, J. Fluid Mechan., 60, 285 (1973).

13. Yu.Lingart, M.Pankevich, Theory and Practice of Large Size Industrial Crystal Growth of Optical Materials, RT+RS SERVIS, Prague (2012) [in Russian].

14. E.R.Dobrovinskaya, L.A.Lytvynov, V.Pishchik, Sapphire. Material, Manufacturing, Applications, Springer Science+Business Media, LLC (2009).

15. M.A.Maurach, B.S.Mitin, Liquid Oxides, Metallurgiya, Moscow (1979) [in Russian].

16. P.-F.Paradis, T.Aoyama, S.Yoda et al., J. Crystal Growth, 249, 523 (2003).

17. A.Golubovic, S.Nikolic, R.Gajic et al., Chem. Soc., 67, 4 (2002).

18. A.A.Kaminskii, Laser Crystals: Their Physics and Properties, Springer, Berlin (1990).

19. B.L.Timan, O.D.Kolotiy, E.R.Dobrovinskaya, V.V.Pishchik, Crystallography, 23, (1978).

20. ANSYS, Inc. ANSYS User's Guide Documentation.

21. S.V.Nizhankovskyi, A.V.Tan'ko, N.S.Sidelnikova, G.T.Adonkin, Cryst.Res.Technol., 50, 223 (2015). 